\title{
CLASSIFICATION OF MODALITY FUNCTION AND ITS APPLICATION TO JAPANESE LANGUAGE ANALYSIS
}

\author{
Shozo NATTO, Akira SHIMAZU, and Hirosato NOMURA \\ Musashino Electrical Communication Laboratories, N.T.T. \\ 3-9-11, Midori-cho, Musashino-shi, Tokyo, 180, Japan
}

\begin{abstract}
This paper proposes an analysis method for Japanese modality. In this purpose, meaning of Japanese modality is classified into four semantic categories and the role of it is formalized into five modality functions. Based on these formalizations, information and constraints to be applied to the modality analysis procedure are specified. Then by combining these investigations with case analysis, the analysis method is proposed. This analysis method has been applied to Japanese analysis for machine translation.
\end{abstract}

\section{Introduction}

Since the meaning of a sentence consists of both proposition and modality, ${ }^{|2|}$ analysis of modality is as indispensable as that of proposition for natural language understanding and machine translation. However studies on natural language analysis have mainly concerned with the propositional part, and algorithms for analyzing modality have not yet been sufficiently developed. The aim of this paper is to clarify the function of modality and to propose a method for analyzing the modality in Japanese sentences.

Structure of a Japanese complex sentence can be formalized roughly by iterative concatenation of simple sentences. The simple sentence consists of cases and a predicate. The cases have surface representations of noun phrases or adverb phrases while the predicate has that of verib or adjective or adjective verb. A noun phrase is defined as the recursive concatenation of noun phrase or that of embedded sentence. We have employed the case structure as a basic meaning structure for a simple sentence, and extended it to retain the construction of complex sentences mentioned. Modality is additive information represented by auxiliary words such as modal particles. encing particles, and auxiliary verbs and sentence adveris. The modal particle is attached to a noun phrase or a sentence element while the ending particle is attached to the end position of a sentence. The auxiliary verb inmediately follows a verb phrase. Modality represented in such grammatically different context is incorporated into the case structure, and the result construction is named as an extended case structure $^{[7]}$ which enable us to propose a uniform framework for analyzing both proposition and modality.

In this paper, we first classify modality into four semantic categories. Second, we define five modality functions using the logical representation of the meaning and then characterize the roles of each function. Third. we specify hard problems to be resolved in modality analysis. Fourth, we list the information and constraints to be considered in establishing the procedure of modality analysis. Then, we propose a method for analyzing modality based on these investigations. Finally, we exemplify the analysis by showing translations from Japanese into English. The method has been used to analyze Japanese sentences in a machine translation system. ${ }^{\text {?i }}$

\section{Classification of modality}

Traditionally, modality has been classified into three categories, i.e. tense, aspect and modal: $: 1$ This classification is not sufficient for the deep analysis of the meaning structure of a sentence, however, because it does not account for the role of Japanese modal particles. Adding this role, we expand this classification into four categories, namely tense, aspect, modal and implicature shown in Table 1. Each category can be further classified into subcategories, and those are shown in Table 2 through Table 5 (Each table gives bolh examples of Japanese expressions and their English equivalents). Our classification of modality features two characteristics concerning the assignment of adverbs and modal particles :

(1) Among the two kinds of adverbs, namely sentence adverbs and case adverbs, we assign sentence adverbs to modality while case adverbs to case relations. Sentence adverbs are classified into three subcategories in the modal

\begin{tabular}{|c|l|}
\hline Categnries & \multicolumn{1}{c|}{ Table 1. Four categories of Modality } \\
\hline Tense & $\begin{array}{l}\text { temporal view of a event relative to the speaking } \\
\text { ume }\end{array}$ \\
\hline Aspect & $\begin{array}{l}\text { state of events viewed from time progress at a } \\
\text { sfecified time point }\end{array}$ \\
\hline Modal & $\begin{array}{l}\text { speaker's or agent's attitude or judgement to the } \\
\text { occurrence of events }\end{array}$ \\
\hline Implicature & $\begin{array}{l}\text { implicative meaning represented by modal } \\
\text { particles }\end{array}$ \\
\hline
\end{tabular}


category : [evaluation], [judgement] and [statement-manner]. (Traditionally, all adverbs are assigned to modality.)

(2) Modal particles are assigned to modality and are classified into a distinct category, implicature (They have been usually discussed separately from modality $)^{[3 / 4 !}$.

\section{Modality functions and their roles}

By employing logical expression as the representation of the meaning structure, we can define modality functions as operations on logical expressions in strict terms. In the past, studies on modality analysis in logical framework treated each type of modality individually. ${ }^{(5161}$ Here, we deal with it, however, as a whole and combine it with the propositional structure so that we can provide a uniform framework for the representation and the analysis of the meaning structure. In this purpose we employ the higher order modal logic formalism. (i)

In this regard, we introduce the five types of modality functions, which add or modify modality :

(1) addition of the modality operator.

(2) surface modification of the case structure,

(3) semantic modification of the case structure,

(4) determination of the scope of negation.

(5) addition of the implicative meaning.

We will now discuss the roles of each type of modality function respectively by indicating their logical representations.

\subsection{Addition of the modality operator}

This is the most fundamental function and it simply adds the modality meaning to the propositional meaning. In the following two sentences. (s1) has no modality while (s2) has modality :

(s1) Hiroko ga hashiru. (Hiroko runs.) Run(Hiroko),

1 In the tollowing, each example sentence is succeeded by an Einglish translation and a logical representation of the meaning.
Table 3. Tense

\begin{tabular}{|l|c|c|}
\hline \multicolumn{1}{|c|}{ Meaning } & $\begin{array}{c}\text { Japanese } \\
\text { expression }\end{array}$ & \multicolumn{1}{c|}{ English expression } \\
\hline Past & ta & ed (past tense) \\
\hline Non-past & ru & present tense, or future tense \\
\hline
\end{tabular}

(s2) Hiroko ga hashit teiru. (Hiroko is running.) [durative] Run(Hiroko).

(s2) is obtained by adding the durative aspect operator "teiru (progressive)" to (s1) ${ }^{(*)}$.

\subsection{Surface modification of the case structure}

This does not change the logical meaning structure even when the surface structure is modified. However higher level information such as focus and attention is sometimes added.

The passive auxiliary verb "reru" or "rareru" can modify the surface case structure without changing the logical meaning structure. The focus is usually placed on the subject part of the passive sentence, as follows :

(s3) Hiroko ga yasai wo taberu.

(Hiroko eats vegetables.),

$\exists x($ Vegetable( $x) \wedge$ Eat(Hiroko, $x)$ ),

(s4) Yasai ga Hiroko ni tabe rareru.

(Vegetables are eaten by Hiroko.),

$\exists x(($ Vegetable( $x) \wedge$ Eat(Hiroko. $x)) \wedge\{$ Focus $(x)\})$,

where the predicate Focus $(x)$ signifies that the focus is placed on the argument $x$.

\subsection{Semantic modification of the case structure}

This results in one of the two alternatives:

(a) one argument is added to the original predicate,

(b) a higher order predicate is introduced.

Both changes are equivalent in meaning but the way of representing the change is different.

The following fragments of modality cause the semantic modification of the case structure :

li causative ("seru" or "saseru"),

2) affected-passive ("reru" or "rareru"),

3) hope ("tehoshii" and "temoraitai").

4) request ("temorau"),

5) benenit ("tekureru" "teageru", and "teyari").

Tabie 2. Aspect (1 /dot/ means concutenation, and do means empty character.)

\begin{tabular}{|c|c|c|}
\hline Meaning & Japaneste expression & Eruglish expression \\
\hline Inchoative & -hajimuru, -kakeru. -dasu & $\begin{array}{l}\text { linchoative verbl hegin, commence, start: 'set about - -ing', } \\
\text { fail to, cume to, taike to }\end{array}$ \\
\hline Just-beîre-inchoutive & $\begin{array}{l}\text { (-hajimers. -kake: u. -dasul (10koro, bakaril, } \\
\text { uiosiru, toknro, bakari }\end{array}$ & be goirg to. be zoing to + [inchoative verb] \\
\hline Iust-after-inchoutive & i-ha ime. -kake, -dashil-ta-(tokoro, takari) & just have [inchoative verbl-en \\
\hline Durative & $\begin{array}{l}\text { - teiru, - leoru, - tsusukert, - tesrutokoro, } \\
\text {-teit.u, - isutsuaru }\end{array}$ & $\begin{array}{l}\text { If dam } \\
\text { vertive verbi go on and on, over and over, (repetition of verb) }\end{array}$ \\
\hline lierative & - leirs, - lenru, - tsuzukeru & verb reoresnnting repetition of action (durative verb) \\
\hline Terminative & -owiru, -oeru, -teshimau & jaffected verbl cease, finish, ieave off, discontinue, 'stop - -ing' \\
\hline Just-before-termin:. is & (-owaru, -oeru, -teshimau)-(tokoro, bakari) & be going $: 0+[$ affected verb $\mid$ \\
\hline$\therefore$ ust-after-terminative & (-owat, -oe, -teshimat, $\Phi) \cdot \mathrm{La} \cdot($ tukoro, bakari) & just have [affecteri verb]-en \\
\hline Terruinative-state & ( owat, -oe, - teshimat, $\phi) \cdot$ teiru & have t.en \\
\hline
\end{tabular}


For an example, the causative auxiliary verb "seru" or "saseru" results in (a) the addition of the causative agent, or (b) the introduction of a second-order predicate $\operatorname{CAUSE}(x, y)$ in which argument $x$ represents the causative agent and argument $y$ represents a predicate, as follows :

(s5) Taro ga Hiroko ni yasai wo tabe saseru.

(Taro makes Hiroko eat vegetables.)

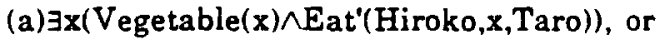

(b) $\exists \mathbf{x}$ (Vegetable(x)^CAUSE(Taro,

Eat(Hiroko, $x$ ))),

where the predicate $\operatorname{Eat}^{\prime}(x, y, z)$ is obtained by adding the argument $z$ corresponding to the causative agent to the predicate Eat $(x, y)$ in (s3).

For another example, though the auxiliary verb "reru" or "rareru" has five meanings, namely, "passive". "affected-passive", "ability". "respective" and "spontaneity", "passive" meaning among them falls into type (2) above while "affected-passive" meaning falls into this type and the affected-agent is added :

(s6) Taro ga Hiroko ni yasai wo tabe rareru.

(Taro was 'aduersely) affected by Hiroko's eating vegetables.)

(a) $\exists x$ (Vegetable( $x) \wedge$ Eat"(Hiroko,x.Taro)), or

(b) $\exists x($ Vegetable( $x) \wedge$ AFFECTED-PASSIVE

(Taro,Eat(Hiroko, $x)$ )).

\subsection{Determination of the scope of negation}

Table 5. Implicature

\begin{tabular}{|l|l|l|}
\hline \multicolumn{1}{|c|}{ Meaning } & \multicolumn{1}{|c|}{ Japanese expression } & \multicolumn{1}{c|}{$\begin{array}{c}\text { English } \\
\text { expression }\end{array}$} \\
\hline Limitation & $\begin{array}{l}\text { shika, kiri, dake, bakari, } \\
\text { made, kurai }\end{array}$ & only \\
\hline Degree & dake, bakari, hodo, kurai & as, about \\
\hline Extreme-example & sae, demo, datte, made & even \\
\hline Stress & sae, ha, mo, koso & even \\
\hline Example & demo, nado, nari & for example \\
\hline Parallel & yara, ya, mo & and \\
\hline Addition & sae, made & also \\
\hline Selection & nari, ka & or \\
\hline Cncertainty & yara, ka & some \\
\hline Distinction & ha & as for \\
\hline
\end{tabular}

The modal particle "wa" determines the role of the auxiliary verb "nai" as a partial negation while the case particle "ga" determines it as total negation. In the following sentences, (s9) is partially negated while (s8) is totally negated:

(s7)Zen'in ga kuru. (Everybody comes.) $\forall x(S(x) \supset$ Come $(x))$,

(s8)Zen'in ga ko nai. (Nobody comes.) $\forall x(S(x) \supset \neg$ Come $(x))$,

(s9)Zen'in wa ko nai. (Not everybody comes.) $\neg \forall x(S(x) \supset \operatorname{Come}(x))$,

where the predicate $S(x)$ denotes "zen'in lall the persons)".

Table 4. Modal

\begin{tabular}{|c|c|c|c|c|c|}
\hline Meaning & Japanese expressiun & English expression & Meaning & Japanese expression & English expression \\
\hline Vegation & nai, zu & not, never & Try & temiru & try \\
\hline Ability & $\begin{array}{l}\text { dekiru, uru, reru. } \\
\text { rareru }\end{array}$ & $\begin{array}{l}\text { can, be able to, } \\
\text { be possible }\end{array}$ & Command & $\begin{array}{l}\text { nasai, [imperative } \\
\text { form of verb] }\end{array}$ & $\begin{array}{l}\text { Iimperative form of } \\
\text { verb! }\end{array}$ \\
\hline Spontaneity & reru, räreru & heccme to & Question & \multirow[t]{2}{*}{ ka } & \multirow{2}{*}{\begin{tabular}{|l} 
linterrogative \\
transformation
\end{tabular}} \\
\hline Obligatoriness & $\begin{array}{l}\text { nakerebanaranai, } \\
\text { nebanaranai. bekida }\end{array}$ & $\begin{array}{l}\text { must, should. } \\
\text { have to }\end{array}$ & \multirow{2}{*}{$\begin{array}{l}\text { Request } \\
\text { (io 2nd person) } \\
\end{array}$} & & \\
\hline Vecessity & hitsuynugaaru & be necessary & & tekure, retai & piease ... \\
\hline Inevitabulity & zaruwoenai, hokina: & cannol help ...ing & Permission & Leyoi & may.can \\
\hline \multirow{2}{*}{ Preference } & \multirow{2}{*}{$\begin{array}{l}\text { hougayoi. } \\
\text { nikoshitakotohanai }\end{array}$} & \multirow{2}{*}{ may well } & Invitation & $u$ & Let's, Shall we \\
\hline & & & Causation & seru, saseru & make la person " do \\
\hline Sufficiency & $\begin{array}{l}\text { saesurebayoi. } \\
\text { bajuubunda, bayoi }\end{array}$ & be enough & $\begin{array}{l}\text { Request } \\
\text { ito 3rd person } 1 \\
\end{array}$ & Lemorau & $\begin{array}{l}\text { get la person/to do. } \\
\text { have }\end{array}$ \\
\hline Stress & noda, nodearu & do & \multirow{2}{*}{ Passive } & \multirow{2}{*}{ reru, rareru } & \multirow{2}{*}{$\begin{array}{l}\text { [passive } \\
\text { iransformation] }\end{array}$} \\
\hline Certain presumption & hazuda. nichigainui & must & & & \\
\hline Encertain conclusion & youda. souda & he likely & Affected-passive & reru. rareru & $\begin{array}{l}\text { [affected-passive } \\
\text { iransformation] }\end{array}$ \\
\hline ¿resumption & rashii & seem & Benefit & tekureru & have la person) to do \\
\hline Guess & $\begin{array}{l}\text { u, you. darou, } \\
\text { toomowarers }\end{array}$ & think & Politeness & desu, masu & - \\
\hline Uncertain-guess & kamoshirenai & may & Respect & reru, rareru & - \\
\hline Hearsay & souda & $\begin{array}{l}1 \text { hear that ... } \\
\text { I. is sairi that ... }\end{array}$ & [Evaluation & $\begin{array}{l}\text { saswainimo, } \\
\text { zannennakotoni, } \\
\text { odoroitakntoni, .. }\end{array}$ & $\begin{array}{l}\text { fortunately, } \\
\text { regretably, } \\
\text { to our surprise, .. }\end{array}$ \\
\hline Intention & $\begin{array}{l}\text { 1. sumorida. } \\
\text { utoshiteiru }\end{array}$ & be going to, will. & \multirow{2}{*}{ [Sudgement] } & \multirow{2}{*}{$\begin{array}{l}\text { osuraku, kanarazu, } \\
\text { akiraxani, omouni, ... }\end{array}$} & \multirow{2}{*}{$\begin{array}{l}\text { perhaps, surely, } \\
\text { evidently, } \\
\text { in my opinion, ... }\end{array}$} \\
\hline Plan & $\begin{array}{l}\text { yoteidearu, } \\
\text { t.otonishiteiru }\end{array}$ & have a plan to & & & \\
\hline Hope & $\begin{array}{l}\text { tai. tehoshii, } \\
\text { temoraitai }\end{array}$ & hope, want & [Statement-manner] & $\begin{array}{l}\text { genmitsuniitte, } \\
\text { yousuruni, } \\
\text { hontounotokoro, ... }\end{array}$ & $\begin{array}{l}\text { in short, } \\
\text { strictly speaking. } \\
\text { in all fairness.... }\end{array}$ \\
\hline
\end{tabular}




\subsection{Addition of the implicative meaning}

An extra logical formula corresponding to the implicative meaning is added by modal particles such as "shika (only)" and "dake (only)" as in :

(s10) Hiroko wa yasai shika tabe nai.

(Hiroko eats nothing but vegetables.)

$\exists x($ Vegetable $(x) \wedge$ Eat(Hiroko, $\mathbf{x})$ )

$\wedge \forall x(\neg \operatorname{Vegetable}(x) \supset \neg \operatorname{Eat}($ Hiroko, $x))$.

\section{Problems in modality analysis}

\subsection{Ambiguity of the modality meaning}

(1) Ambiguity due to multiple meaning

The aspect expression "teiru" has three different kinds of meanings, that is, the "durative", "iterative" or "terminative-state" aspects. For example,

(s11)Hiroko ga yasai wo tabe teiru.

(Hiroko \{is eating, eats and eats, has eaten\} vegetables.)

$\exists x($ Vegetable( $x)$

$\wedge\{$ [durativel,[iterative],[terminative-state]\} Eat(Hiroko, x)).

(2) Ambiguity concerned with case structure

As stated in Section 3.3 above, the auxiliary verb "reru" or "rareru" has five meanings, and, among them, the "passive" and "affected-passive" meanings result in modification to the case structure. Therefore, disambiguation of the meaning of "reru" or "rareru" has a close relationship to analysis of the propositional meaning.

Moreover the auxiliary verb "rareru" in the following (s12) means "respect", and that in (s13) means "passive", respectively. Whereas, both expressions are same except the additional meaning of respect and focus, as follows :

(s12)Sensei ga yasai wo tabe rareru.

(The teacher eats vegetables.)

$\exists x(\operatorname{Vegetable}(x) \sim$ Eat (the-Teacher, $x))$

$\wedge$ Respect(Speaker, the-Teacher),

(s13)Yasai ga sensei ni tabe rareru.

(Vegetables are eaten by the Teacher.)

$\exists x(($ Vegetable $(x) \wedge$ Eat the-Teacher, $x))$

$\wedge($ Focus $(x)\})$,

where the predicate Respect $(x, y)$ means that $x$ respects y.

\subsection{Scope of modality}

Even if the main clause has a negative expression, it does not always mean that the main clause is negated. Sometimes the subordinate clause is negated. We call this phenomenon the transfer of negation. Furthermore even if modality involved is not negation, it sometimes affects the subordinate clause.

Although the main clause in the following (s14) is not usually negated, the subordinate clause is.
Nevertheless, the tense information in the main clause has an effect on the subordinate clause. (s14) is constructed from (s14-1) and (s14-2) by a simple coordinate conjunction, however the corresponding logical expression is not a simple concatenation of each logical expression :

(s14)Taro wa hige wo sot te kaisha e ika nakat ta. (Taro went to the company without shaving.) [past] $\neg$ Shave(Taro, beard) $\wedge$ [past]Go(Taro,Company),

(s14-1)Taro wa hige wo soru. (Taro shaves beard.) Shave(Taro, beard),

(s14-2)Taro wa kaisha e ika nakat ta. (Taro did not go to the company.) [past] $\neg \mathrm{Go}$ (Taro, Company).

(s8) and (s9) also exemplify the problem for determining the scope of negation.

\subsection{Treatment of implicative meaning}

Modal particles such as "shika (only)" and "sae (even)" convey individual implicative meaning. In order to obtain the logical representation of the implicative meaning, we are forced to provide different formulae expressive of the each meaning of each modal particle. For example, if we assign the formula $(\Pi)$ to the expression "shika...nai" which consists of the modal particle "shika" and auxiliary verb "nai", we get the logical representation of the sentence $(\$ 10)$ by the procedure of $\lambda$-calculus shown in Fig. 1.

$$
\begin{aligned}
(\text { II }) " \text { shika...nai" } \rightarrow A P \lambda Q \lambda R(\exists x(P(x) & \wedge R Q(x)) \\
& \wedge \forall x(\neg P(x) \supset R \rightarrow Q(x))) .
\end{aligned}
$$

As can be seen from the example, the logical formula for the implicative meaning is very individual. This concludes that specification of it for each meaning is very complicated and hard, and a more effective method is therefore needed.

5. Information and constraints on modality
analysis

\section{(1) Lexical meaning}

The lexical meaning assigned to each modality expression is the most fundamental information. So we need to specify and provide it. For example, the lexical meaning of the auxiliary verb "ta" is generally the "past" tense as in :

(s15)Hiroko ga hashit ta. (Hiroko ran.) [past]Run(Hiroko).

\section{(2) Predicate features}

Predicate features are available for disambiguating the meaning of modality.

Though the aspect auxiliary verb "teiru" is ambiguous in meaning, we can resolve it by using predicate features such as the "stative", "continuous" and "spontaneous", as in : 
(s16)Hiroko ga hashit teiru. (Hiroko is running.) [durative]Run(Hiroko),

(s17)Akari ga kie teiru. (The light is turned off.) [terminative-state]Turn-off(the-Light),

where the verb "hashiru (run)" has the "continuous" feature while the verb "kieru (turn off)" has the "spontaneous" feature. The aspect expression "teiru" following a "continuous" verb usually means the "durative" aspect, and "teiru" following a "spontaneous" verb usually means the "terminativestate" aspect.

The "spontaneity" meaning of "reru" or "rareru" is realized only when it follows the verbs having spontaneity feature such as "omoidasu (remember)" and "anjiru (care)".

\section{(3) Noun phrases and adverbs}

Some kinds of noun phrases, adverbs, and their semantic categories can be utilized to disambiguate the meaning of modality, when they occur simultaneously with it.

(s18)Hiroko ga yasai wo ima tabe teiru.

(Hiroko is eating vegetables now.) $\exists \mathbf{x}($ Vegetable $(x)$

$\wedge$ [durative]Eat"(Hiroko, $x$, now)).



Fig. 1. Logical analysis of the sentence (s10)
(s19)Hiroko ga yasai wo sudeni tabe teiru. (Hiroko has already eaten vegetable.) $\exists x($ Vegetable $(x) \wedge[$ terminative-state]

Eat"'(Hiroko,x,already)).

In the above examples, the adverb "ima (now)" is concerned with the "durative" aspect, while "sudeni (already)" is concerned with the "terminative-state" aspect. The argument $z$ of the predicate Eat'" $(x, y, z)$ represents time information.

\section{(4) Modal particles}

As discussed in Section 3 (sentences (s8) and (s9)), the modal particle "wa" occurring simultaneously with negation suggests partial negation.

\section{(5) Conjunctive relations}

Conjunctive relations are related to the scope of modality. If the subordinate clause has the following conjunctive relations represented by

(a) the conjunctive particle "te", or

(b) a relative noun such as "toki (tıme)" or "mae

(before)" modified by embedded sentences.

the transfer of negation can be predicted as in sentence (s14). Otherwise, the transfer will never occurs as follows:

(s20)Taro wa hige wo sot ta ga

$$
\text { kaisha e ika nakat ta. }
$$

(Though Taro shaved his beard. he did not go to the company.) [past]Shave(Taro,beard) $\wedge($ past $]$ - Go(Taro,Company).

(6) Semantic relations between the subordinate clause and the main clause

This information is used to determine the scope of negation in the main clause. In the subordinate clause with the conjunctive particle "te", if the event expressed by it is subsidiary for the occurrence of the event in the main clause, the transfer of negation can occur. On the other hand, if the subordinate event is indispensabie to the occurrence of the main event, the transfer never occurs. For example, in (s14), since the modifier event Shave(Taro.beard) is a subsidiary event for the occurrence of the main event Go(Taro.Company), the transfer of negation is possible. In the following sentence (s21), however. since the event GorTaro, Washington) is an indispensable event for the occurrnece of the main event See(Taro, White-House), the transfer is impossible:

(s21)Taro wa Washington e it te

White House wo mi nakat ta.

(Taro did not see the White House

when he went to Washington.)

[past]Go(Taro, Washington) $\wedge$ [past] $\neg$ See(Taro, the-White-House). 


\section{Modality analysis}

\subsection{Strategy of the modality analysis}

Considering the five modality functions defined in Section 3, it is apparent that the logical analysis method alone is not effective for modality analysis. There are three reasons for this :

(1) Reference to other expressions is needed to resolve the ambiguity of the modality function,

(2) Structural modification occurs when the scope of negation is transferred.

(3) Analysis of the implicative meaning sometimes cause the change of logical expression.

There remains, however, the problem of taking the individuality of each modality into account. For some kinds of modality, the result of the case analysis or the conjunctive analysis is used to analyze it. These represent the reasons why we propose an analysis method consisting of the following three modules combined with the case analysis and the conjunctive analysis :

(1)pre-case-analysis : activated before the case analysis,

(2)post-case-analysis : activated after the case analysis.

(3) post-conjunctive-analysis : activated after the conjunctive analysis.

The relationship of these three modules to the case analysis and the conjunctive analysis is shown in Fig. 2.

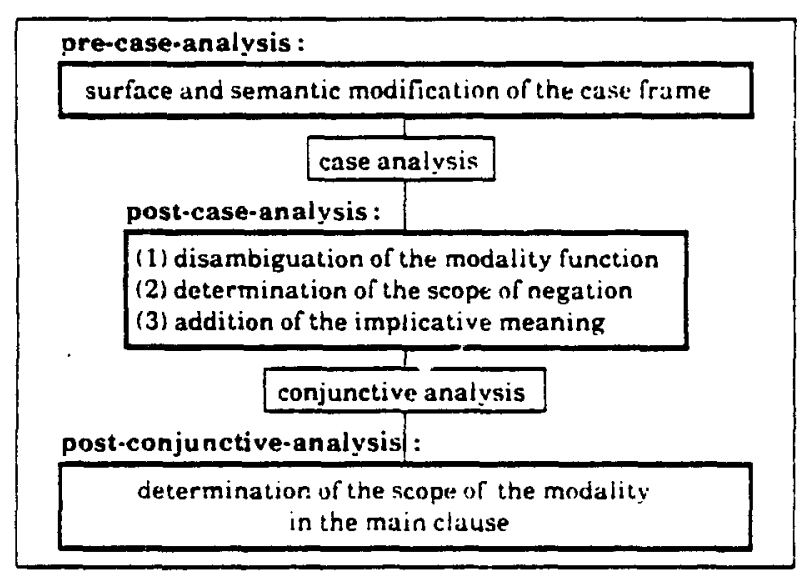

Fig. 2. Framework of the modality analysis

\subsection{Algorithms of each sub-analysis}

(1) Pre-case-analysis

The modality whose analysis requires only lexical mearing or which causes a change of the case structure is analysed at this stage. The case frame to be assigned to the predicate is modified by utilizing the result of this analysis before starting the case analysis. As for the semantically ambiguous auriliary verb "reru" or "rareru", its role is only predicted at this stage, because it is also concerned with the modification of the case structure. After case analysis, the plausibility of the prediction is evaluated. The modification of the case frame is as follows :

(a) For the "passive" meaning of "reru" or "rareru" (which causes a surface change to the case structure as mentioned in Section 3.2), the object case of the original case frame is changed into the surface subjective case, and the modality category "passive" is assigned to the meaning structure. If two object cases exist, two possible modifications are performed.

(b) With the modality causing a semantic change to the case structure (for the modality function stated in Section 3.3), a new case is added as follows:

(bl)For the "causative", "affected-passive", "hope" or "request" meaning : A new agent (e.g. causative-agent / affected-agent) is added, and the case particle of the original subjective case is changed from "ga" to "ni".

(b2)With the "benefit" meaning : A beneficiary case is added. The case particle in this case is "ni".

Also the modality category corresponding to each meaning (e.g. "causative", "affectedpassive") is assigned to the meaning structure.

\section{(2) Post-case-analysis}

The modality whose analysis requires case structure information is analyzed at this stage. This module determines the function of the modality as follows:

(a) If the category of the modality expression is unique. this category is assigned to the meaning structure.

(b) If a dacmon (a procedure to resolve ambiguities by using heuristics) is attached to the modality expression, it performs the three tasks :

(b1) disambiguating the function of the modality expression,

(b2) deternining the scope.

(b3) adiding the implicative meaning.

The daemon utilizes the information mentioned in (1) (4) in Section 5. For example, a daemon attached to the aspect expression "teiru" works as shown in Fig. 3.

\section{(3) Post-conjunctive-analysis}

Following the conjunctive analysis between the subordinate clause and the main clause, this module is activated to determine whether the modality in the main clause also operates on the subordinate clause. This module utilizes heuristics consisted of all of the 


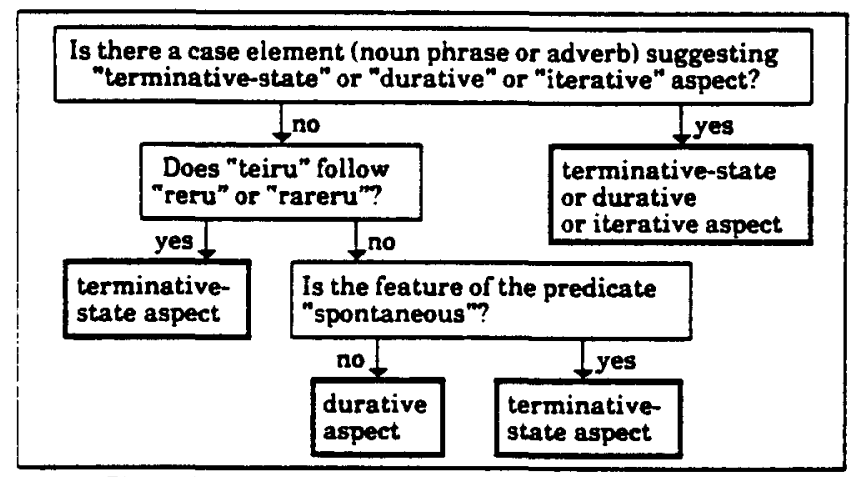

Fig. 3. Daemon which disambiguates the meaning of the aspect expression "teiru"

information presented in Section 5. An example of heuristics which analyze the scope of the auxiliary verb "ta" is shown in Fig. 4.

For negation in the main clause, the transfer of negation is considered. Whether or not the modifier event is subsidiary for the occurence of the main event is tested using the semantic relations assigned to the predicate of the main clause.

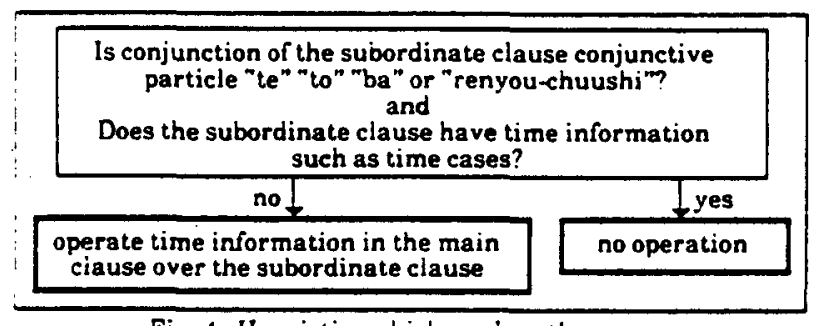

Fig. 4. Heuristics which analyse the scope of the auxiliary verb "La"

\subsection{Application to Japanese analysis}

\section{(1) Extended case analysis}

We have already proposed a method named extended case analysis for Japanese sentences. ${ }^{[7 \mid}$ Input to the extended case analysis is an ordered list of word frames produced by a morphological analysis. The analysis begins to predict a constituent construction of the sentence to be analyzed by utilizing syntactic structure patterns, and then enter into the detail analysis of semantic relations between pairs of the modifier and the modificant by utilizing semantic relation frames. There are four types of the semantic relations, namely, case relation, noun concept relation, embeding reiation and conjunctive relation. All of these semantic relations are analyzed in a uniform framework. The both analyses go on iteratively and/or recursively from a small chunk of constituents to large one. Each iteration and recursion executes both the prediction of the syntactic structure and the analysis of semantic structure. The modality analysis is incorporated into those processes.

Let us show the modality analysis process for the following example sentence :
(s22)Niku wa nokot teite, yasai dake ga Hiroko ni tabe rare teita. Meat had remained, and only vegetables had been eaten by Hiroko.

At first, it is analysed that this sentence is a complex sentence by utilizing syntactic structure patterns. After semantic structures of the modifier and the main clause are analysed, conjunctive relation between these clauses is analyzed. Now, we show analysis of the main sentence.

The following case elements and a predicate are analysed by applying structure patterns before starting case analysis :

$$
\begin{aligned}
& \text { case1 = "yasai", "ga", "dake", } \\
& \text { case2 = "Hiroko", "ni", } \\
& \text { predicate = "taberu", "rareru" , "teiru", "ta", }
\end{aligned}
$$
where "dake", "rareru", "teiru", and "ta" are modality expressions. "Hiroko" and "yasai" have semantic categories, [human] and [food] respectively in each word frame.

\section{(2) Modification of case frame}

Case frame is prepared for each meaning of each predicate. An intrinsic case frame for the verb "taberu (eat)" is as follows (Optional cases such as time and place are omitted here):

[the intrinsic case frame of the verb "taberu (eat)"] :

$$
\begin{aligned}
& \text { Agent }=\text { [human }], " g a ", \\
& \text { Object }=[\text { food }],
\end{aligned}
$$

Each case slot in the case frame is assigned semantic categories and case particles as constraints to be satisfied by the filler.

The following alternative case frames produced by modifying the intrinsic frame are also prepared before starting case analysis because of the existence of the auxiliary verb "rareru" :

["passive" modification of the case frame] :

$$
\text { Agent = [human], "ni", }
$$

$$
\text { Object }=[\text { food }] \text {, "ga", }
$$

["affected-passive" modification of the case frame] :

Affected-agent $=$ [human], "ga",

Agent = [human], "ni",

Object $=$ [food] , "wo".

These three case frames are examined whether each case element in the sentence satisfies constraints. As a result, in this case, "passive" modification case frame is selected as a best matching, and case role of each case element is determined as follows :

$$
\text { case } 1 \text { = Object, } \text { case } 2=\text { Agent. }
$$

This result is showing that the meaning of "rareru" is "passive".

\section{(3) Determination of meaning of modality}

Modality by modal particles in case elements and auxiliary verbs are analyzed. Analysis of "teiru" is 
performed by the heuristics shown in Fig. 3, where the meaning is determined as "terminative-state" judging from the fact that "teiru" follows "rareru". The meaning of the modal particle "dake" is multiple, that is, "limitation" and "degree". In this case, "limitation" is selected by heuristics.

(4) Determination of scope of modality in the main clause

After conjunctive analysis between the modifier and the main clause, scope of the auxiliary verb "ta" in the main clause is analyzed. Using heuristics shown in Fig. 4, it is analyzed that "ta" also operates on the subordinate clause.

In a result, the meaning structure of (s22) is obtained as follows :

$\exists x((\operatorname{Meat}(x) \wedge$ [past][terminative-state]Remain $(x))$

$\wedge \exists x(($ Vegetable $(x)$

$\wedge$ (past][terminative-state]Eat $($ Hiroko, $x))$

$\wedge \forall x((\sim$ Vegetable $(x)$

$\supset \neg$ [past)[terminative-state]Eat(Hiroko, $x$ ))

$\wedge\{$ Focus (x)\}).

An English sentence corresponding to this semantic structure is shown in (s22).

\subsection{Virture of modality analysis}

We show contributions of modality analysis to understanding and quality of translation for the following example sentences.

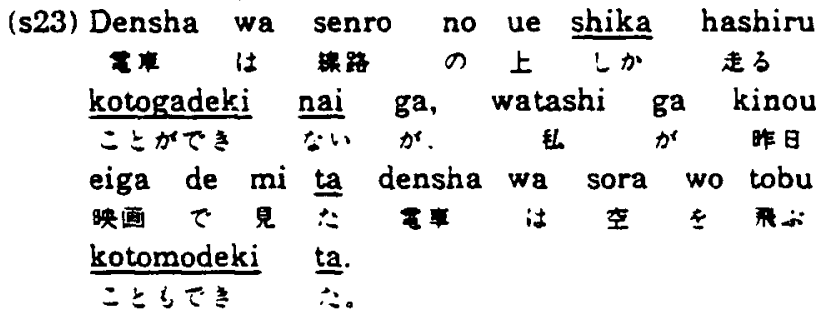

Though a train can run only on a railroad, the train I saw in a movie yesterday could also $h y$.

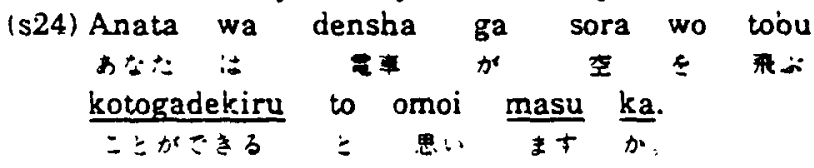

Do you tinink that a train can fly?

(1) [speech act] As shown in (s24), modality contains much information concerning speech act (question, command, guess, intention, etc.). In conversational systems such as qustion answering systems, these meaning can be used for selecting apropriate reactions.

(2) [type of object] Analysis results of aspect or tense are used for determiring the type of objects.

The subordinate clause of (s23) describes a general character of "densha (train)", and the first occurrence of "densha" denotes a generic object. On the other hand, the second occurrence of "densha" is modified by an embedded sentence, and "densha" denotes a specific object which "I saw in a movie yesterday". Like this, if the character of the event is analysed by the analysis of aspect or tense, the character of the objects can be specified.

(3) [translation] As shown in the translated sentences in (s23) and (s24), results of the modality analysis are clearly realized in quality of translated sentences. In these sentences, modality such as "limitation", "negation", "ability", "past", "quetion" appears.

\section{Conclusion}

We proposed an analysis method for Japanese modality. In this purpose, we classified the meaning of modality into four categories, and then defined five modality functions which characterize the role of modality. By employing logical expressions to represent the meaning structure, we could effectively specify the modality function. Though logical expression has the same expressive power as frames or semantic networks, a more concise semantic representation can be realized by this method.

Although we dealt with the modality analysis restricted within the scope of one sentence in this paper, we must investigate the effect of discourse information on the analysis of modality in the future.

We have applied this modality analysis method to the Japanese sentence analysis in the JapaneseEnglish experimental machine translation system, LUTE. [?!

\section{References}

[1] Dowty, D. R., R. E. Wall, and S. Peters : Introduction to Montague Semantics, 1981.

[2] Fillmore, C. J. : Toward a Modern Theory of Case and Other Articles, Japanese edition, 1975.

[3] Karttunen, L. and S. Peters : Conventional Implicature. "Syntax and Semantics" 11, ed. by C.K. Oh and D. A. Dinneen, 1979.

[4] Kubo, S. : A Study of Japanese Adverbial Particles in Montague Grammar, "Linguistic Journal of Korea", vol.7, no.2, 1982.

(5) Keenan, E. : Negative Coreference: Generalizing Quantification for Natural Language, "Formal Semantics and Pragmatics for Natural Languages", ed. by F. Guenthner and S. J. Schmidt, 1979.

[6] Nakau, M. : Tense, Aspect, and Modality, "Syntax and Semantics" 5, ed. by M. Shibatani, 1976.

[7] Shimazu, A., S. Naito, and H. Nomura : Japanese Language Semantic Analyser based on an Extended Case Frame Model, Proc. of 8th International Joint Conference on Artificial Intelligence, 1983. 